\title{
Retrospective analysis of indications of primary caesarean sections done at a tertiary care hospital
}

\author{
Kamna Datta, P. Singh, Namita Chopra*
}

Department of Obstetrics and Gynecology, Dr. RML Hospital, New Delhi, India

Received: 23 May 2019

Accepted: 01 July 2019

*Correspondence:

Dr. Namita Chopra,

E-mail: drnamitachopra@gmail.com

Copyright: (C) the author(s), publisher and licensee Medip Academy. This is an open-access article distributed under the terms of the Creative Commons Attribution Non-Commercial License, which permits unrestricted non-commercial use, distribution, and reproduction in any medium, provided the original work is properly cited.

\begin{abstract}
Background: Caesarean section rates have globally risen above the levels that can be considered medically necessary. The aim of the study is to analyze the rate and indications of caesarean sections for primigravidae in the period 2016 to 2018 at a tertiary care hospital in Delhi.

Methods: It is a retrospective observational study conducted in the Department of Obstetrics and Gynaecology at PGIMER and Dr RML Hospital, New Delhi. A total of 552 caesarean deliveries in primigravidae were studied.

Results: The total deliveries during the study period were 3346 and the total caesarean section rate observed was $30.66 \%$. The caesarean section rate among primigravidae was $29.1 \%$. The rate of caesarean section in primigravidae rose from $22.7 \%$ in 2016 to $39.3 \%$ in 2018 with $17 \%$ increase. Majority of them belonged to the age group 20-30 years $(79.34 \%)$ and $2.53 \%$ were elderly primigravidae. Out of the total number of primigravidae caesarean deliveries, $67.2 \%$ were performed in emergency and $32.7 \%$ were performed electively. Among the emergency caesarean sections performed, $64 \%$ of patients had induced labor and $22 \%$ had spontaneous labor. The most common indication of caesarean section was fetal distress $(19.77 \%)$ followed by arrest of labor (17.87\%) and malpresentations (8.9\%). The short-term caesarean morbidity rate was $25.4 \%$ including one mortality. Wound infection was the most common complication.

Conclusions: Various reasons like changing maternal risk profile increased IVF pregnancies, scientific advances, personal choice and medico legal considerations have been cited for increased caesarean rate. Following evidencebased labor protocols, judicious use of cardiotocography, proper patient selection for labor induction and patient education will contribute in reduction of caesarean sections and related complications.
\end{abstract}

Keywords: Caesarean section, Fetal distress, Indications, Labor, Morbidity, Primigravidae

\section{INTRODUCTION}

Caesarean section rate has been steadily rising worldwide over the last few decades. This trend has not been accompanied by significant maternal and neonatal benefits. What has already been described as the "caesarean birth epidemic" may now be considered a true pandemic emerging issue in mother-child healthcare. ${ }^{1}$ In fact, way back in 1985 the World Health Organization
(WHO) stated: "There is no justification for any region to have caesarean section rates higher than 10-15\%". The increase in caesarian section rate has become a major public health issue not only because it is a burden on health system and strain on families but also because it has long lasting effects on the health of both mother and baby. It has been observed that caesarean deliveries are associated with increased risk of maternal and perinatal morbidity as compared to vaginal deliveries even in low 
risk cases. ${ }^{2,3}$ Recent articles in leading journals support offering women, in whom an accepted medical indication for the procedure does not exist, the right to choose a caesarean section as the mode of delivery that is, a primary elective caesarean section or caesarean section on demand. ${ }^{4,5}$ This is causing upward pressure on caesarean section rate. The factors involved in increase in the rate may include lesser chances of pelvic floor problems post caesarean as well as changes in patient's preferences and in the part that doctors play in decision making. How women view the care they want to receive in labor and delivery may have changed.

Safely reducing the rate of primary caesarean sections will be one of the most effective ways to cure the problem at the root level. Thus, this study was undertaken to identify the areas of intervention in order to curb primary caesarean sections.

The objective of the present study was to find the rate of caesarean deliveries in primigravidae and its contribution to total caesarean rate. To analyze the indications of the caesarean sections done for primigravidae.

\section{METHODS}

It is a retrospective study conducted in Department of Obstetrics and Gynecology, Dr RML Hospital, New Delhi, from January 2016 to December 2018. The data was collected from the hospital birth registry, the medical record section and in-patient files. The total number of deliveries (both vaginal route and caesarean section) along with the total number of caesarean sections from January 2016 to December 2018 were noted to calculate the total caesarean section rate in the hospital. All caesarean sections performed on primigravidae were analyzed in detail.

The total caesarean rate $=$ (total number of caesarean sections in the study period/ total deliveries) $\times 100$

Caesarean rate in primigravida $=$ (caesarean sections in primigravidae/total caesareans) x100

\section{The following parameters were recorded}

- Age of the patient

- Associated maternal morbidity in antenatal period, if any

- Spontaneous labour or induced labour

- Emergency caesarean section or elective basis

- Indication of caesarean sections and the period of gestation

- Maternal complications per-operative and postoperatively.

Descriptive analysis was done for each parameter. Indications of caesarean section were classified as fetal distress, arrest of labor, failed induction, malpresentations, multiple gestation, placenta previa, severe preeclampsia with poor bishop score, severe growth restriction with deranged doppler, precious pregnancy and caesarean on demand. Each indication was analyzed and methods to address each indication and curb caesarean rate are discussed.

\section{Inclusion criteria}

For detailed analysis of caesraean sections in primigravidae

- All primigravidae, including teenage pregnancies as well as elderly group who underwent caesarean section in RML Hospital in the period January 2016 to December 2018

- Booked as well as unbooked pregnancies

- Spontaneous pregnancies as well as conceived by assisted reproductive techniques

- Previous non-viable pregnancies (abortions).

\section{Exclusion criteria}

- Parity more than one (previous normal delivery as well as caesarean sections)

- Period of gestation before viability.

\section{RESULTS}

The total caesarean section rate was calculated to be $30.6 \%$. Caesarean section rate among primigravidae was $29.1 \%$. The Caesarean Sections in primigravidae contributing to total caesarean sections in the study period is $53.8 \%$ (Figure 1). The incidence of caesarean sections among primigravidae showed a clear rise from 2016 to 2018 . It was $22.7 \%$ in $2016,25.3 \%$ in 2017 and $39.3 \%$ in 2018 with $17 \%$ increase. The mean incidence of caesarean section in primigravidae was $29.1 \%$ (Figure 2).

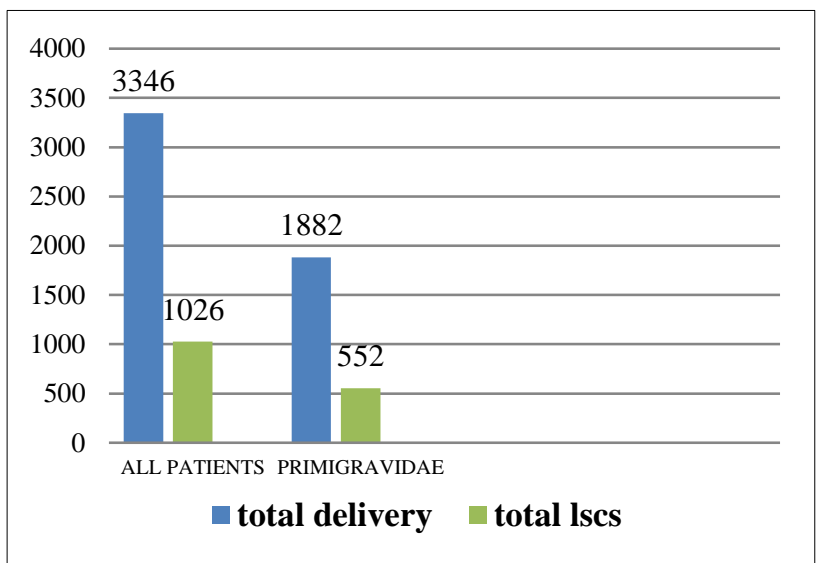

Figure 1: Number of caesarean sections from 2016 to 2018.

The age wise distribution of the subjects showed that majority of primigravidae belonged to the age group 20- 
30 years $(79.34 \%)$ and $2.53 \%$ subjects belonged to age group 35 years and more (Figure 3 ).

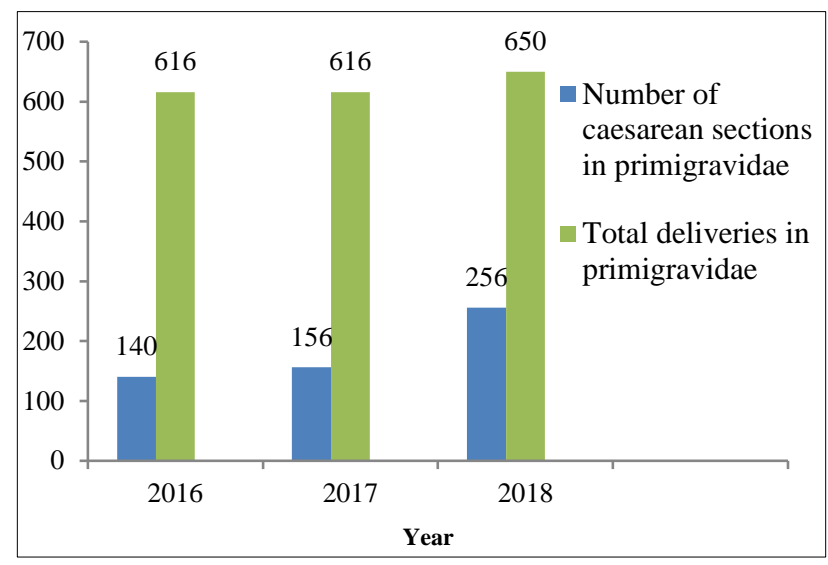

Figure 2: Incidence of caesarean section in primigravidae.

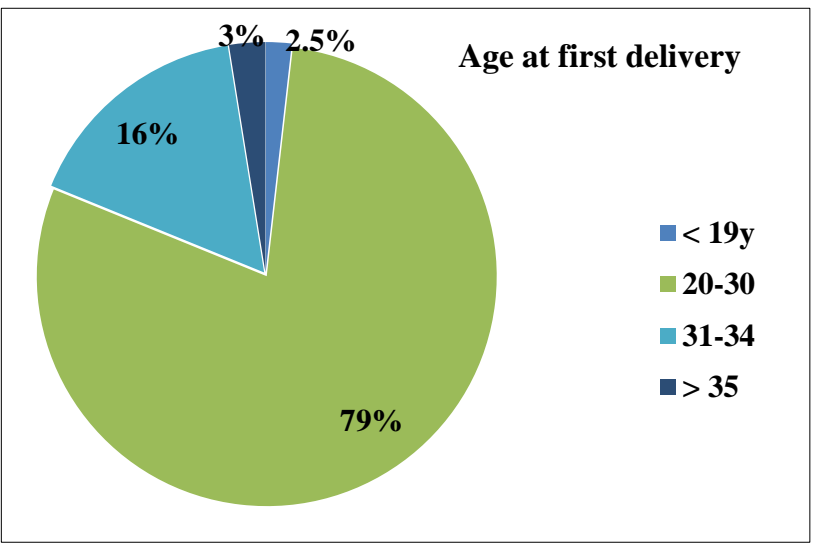

Figure 3: Age distribution (percentage) of primigravidae who underwent caesarean section $(\mathrm{N}=552)$.
Table 1: Emergency versus elective primi caesareans $(\mathrm{N}=552)$.

\begin{tabular}{|lll|}
\hline Caesarean section & Number & Percentage \\
\hline Emergency & 371 & $67.2 \%$ \\
\hline Elective & 181 & $32.8 \%$ \\
\hline Total & 552 & $100 \%$ \\
\hline
\end{tabular}

It was observed that out of total 552 caesarean sections performed in primigravidae, $371(67.2 \%)$ were performed on emergency basis due to various indications like fetal distress, arrest of labor, malpresentations in labor, cephalopelvic disproportion in labor and severe preeclampsia or impending eclampsia and 181 (32.8\%) were done on selective basis (Table 1).

Table 2: Caesarean sections in relation to period of gestation $(n=552)$.

\begin{tabular}{|lll|}
\hline Period of gestation & Number & Percentage \\
\hline preterm $<37$ weeks & 123 & $20.91 \%$ \\
\hline term $37-40$ weeks & 395 & $74.14 \%$ \\
\hline Late term $40-42$ weeks & 34 & $4.94 \%$ \\
\hline Total & 552 & $100 \%$ \\
\hline
\end{tabular}

As expected, majority of caesareans $(74.14 \%)$ were done between 37 to 40 weeks period of gestation, $20.91 \%$ were done at $<37$ weeks period of gestation and $4.94 \%$ were done at 40-42 weeks period of gestation (Table 2). Out of the total emergency operative deliveries 289 patients were in labor. Among them, 209 (56.3\%) of patients had induction of labor and $80(21.5 \%)$ were in spontaneous labor (Table 3).

Table 4: Indications of PRIMI caesarean sections.

\begin{tabular}{|c|c|c|c|c|}
\hline Indications & $\begin{array}{l}\text { Emergency } \\
\mathbf{N}=371\end{array}$ & $\begin{array}{l}\text { Elective } \\
\mathrm{N}=181\end{array}$ & $\begin{array}{l}\text { Number } \\
\mathbf{N}=552\end{array}$ & Percentage \\
\hline Fetal distress & 108 & & 108 & $19.77 \%$ \\
\hline Failed induction & 28 & 14 & 42 & $7.22 \%$ \\
\hline Arrest of labour & 96 & & 96 & $17.87 \%$ \\
\hline Malpresentation & 23 & 30 & 53 & $8.93 \%$ \\
\hline Multiple gestation & 18 & 15 & 33 & $5.70 \%$ \\
\hline Placenta praevia/Ante partum haemorrhage & 8 & 15 & 23 & $1.90 \%$ \\
\hline Cephalopelvic disproportion & 13 & 30 & 43 & $8.17 \%$ \\
\hline Severe pre-eclampsia/eclampsia with poor bishop score & 33 & 16 & 49 & $8.93 \%$ \\
\hline $\begin{array}{l}\text { Severe fetal growth restriction with deranged Doppler and/or } \\
\text { severe oligohydramnios }\end{array}$ & 41 & - & 41 & $10.26 \%$ \\
\hline Gestational diabetes with macrosomia & 10 & 16 & 26 & $4.56 \%$ \\
\hline Elderly primi & & 8 & 8 & $1.52 \%$ \\
\hline Precious pregnancy (Bad obstetric history, IVF conceived) & 4 & 12 & 16 & $2.47 \%$ \\
\hline Caesarean on demand & & 14 & 14 & $2.09 \%$ \\
\hline Total & 371 & 181 & 552 & $100 \%$ \\
\hline
\end{tabular}


Table 3: Emergency caesarean sections-spontaneous labor versus induced labor $(\mathrm{N}=\mathbf{2 8 9})$.

\begin{tabular}{|lll|}
\hline Nature of labor onset & Number & Percentage \\
\hline Spontaneous labor & 80 & $27.68 \%$ \\
\hline Induced labor & 209 & $72.32 \%$ \\
\hline Total & 289 & $100 \%$ \\
\hline
\end{tabular}

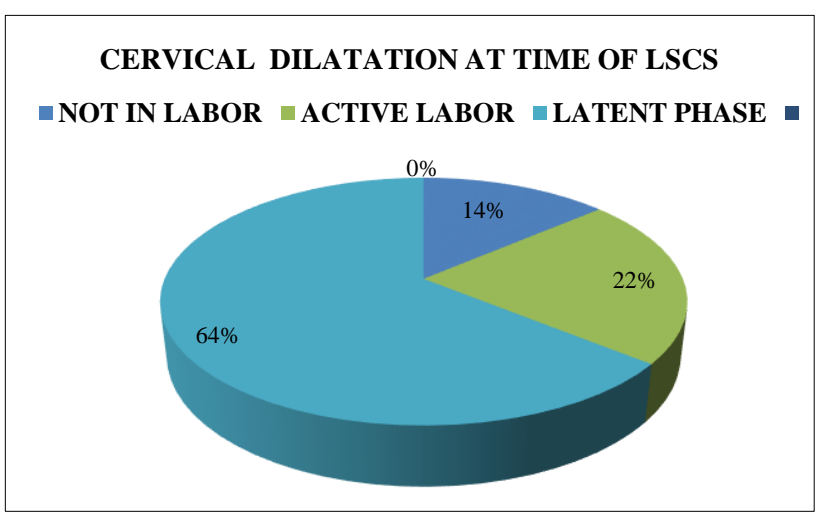

Figure 4: Cervical dilatation at the time of caesraean section (in percentage, total $=\mathbf{1 0 0 \%}$ ).

Table 5: Maternal complications per-operative and post-operative $(\mathrm{N}=552)$.

\begin{tabular}{|lll|}
\hline Complications & $\begin{array}{l}\text { Number of } \\
\text { patients }\end{array}$ & Percentage \\
\hline Spinal headache & 49 & $8.8 \%$ \\
\hline PPH & 27 & $5.2 \%$ \\
\hline Blood transfusion & 14 & $2.5 \%$ \\
\hline Wound infection & 50 & $9 \%$ \\
\hline Post op febrile illness & 11 & $2 \%$ \\
\hline Urinary tract infections & 14 & $2.5 \%$ \\
\hline Systemic infection/sepsis & 1 & $0.2 \%$ \\
\hline Mortality & 1 & $0.2 \%$ \\
\hline
\end{tabular}

The indications of caesarean section in primigravidae (total 552 patients) are described in Table 4. It was seen that most common indication of caesarean in primigravidae was fetal distress-19.77\%, followed by arrest of labor $-17.87 \%$, both on emergency basis. Severe fetal growth restriction with deranged doppler and/or severe oligohydramnios was the third most common indication $(10.26 \%)$. The list was followed by other indications in decreasing trend- malpresentation- $8.93 \%$ (65\% on selective basis and $35 \%$ on emergency basis), severe preeclampsia with poor bishop score- $8.93 \%(70 \%$ on emergency basis), cephalopelvic disproportion (8.1\%), failed induction $(7.22 \%)$, multiple gestation $(5.7 \%)$, gestational diabetes with macrosomia $(4.56 \%)$, precious pregnancy $(2.47 \%)$, caesarean section on demand $(2.09 \%)$ and placenta previa $(1.90 \%)$.

The morbidity rate in caesarean section in primigravidae was $25.4 \%$ with wound infection being the most common $(9 \%)$. Spinal headache was complained by $8.8 \%$ of patients. Post-partum hemorrhage (both intra-operative and post-operative) was the third most common cause of morbidity, accounting for $5.2 \%$ of the cases. Blood transfusion due to excessive loss was required in $2.5 \%$ of the cases (Table 5).

\section{DISCUSSION}

Caesarean section is one of the most commonly performed procedures in the health care services. Consequences of caesarean section can vary from recurrent caesarean section to scar rupture to caesarean hysterectomy. The incidence of placental abnormalities like placenta previa, abruptio placentae and placenta accreta syndrome has also risen as a consequence of previous caesarean section. In fact, this was one of reasons why the increased rate of caesarean deliveries came into light. The increase in primary caesarean section has a multiplier effect on the overall caesarean rate. Hence the alarmingly high rate of primary caesarean section is a cause for immediate concern and serious measures.

The number of caesarean sections is increasing as more attention is focused on neonatal survival and prevention of trauma to the child during delivery in addition to limited family size and expectation of a healthy child at the end of pregnancy.

Table 6: Incidence of caesarean sections in primigravidae.

\begin{tabular}{|c|c|c|c|}
\hline Study & Place & Study period & Caesarean rate \\
\hline Das RK et $\mathrm{al}^{6}$ & Bhubaneshwar & 2017-2018 & $35.45 \%$ \\
\hline M Gupta et $\mathrm{al}^{7}$ & Jaipur & Jan 2016-Dec 2016 & $46.18 \%$ \\
\hline Saxena $\mathrm{N}$ et $\mathrm{al}^{8}$ & Dehradun & Jan 2015-Dec 2015 & $31.40 \%$ \\
\hline R Subhashini et $\mathrm{al}^{9}$ & Vishakhapatnam & Jan 2014-Dec 2014 & $37.25 \%$ \\
\hline Naheed et $\mathrm{al}^{10}$ & Lahore & Jan 2013-Dec 2013 & $57.5 \%$ \\
\hline Yadav $\mathrm{RG}^{11}$ & Vadodra & Jan 2013-Dec 2013 & $28.87 \%$ \\
\hline Singh $\mathrm{G}$ et al ${ }^{12}$ & Agroha & Jan 2012-Dec 2012 & $51.1 \%$ \\
\hline Padmaleela $\mathrm{K}$ et al ${ }^{13}$ & Andhra Pradesh & Apr 2011-March 2012 & $31 \%$ \\
\hline Ji Honglei et al ${ }^{14}$ & China & 2010-2012 & $58.1 \%$ \\
\hline Present study & RML Hospital, Delhi & $2016-2018$ & $29.1 \%$ \\
\hline
\end{tabular}


In the present scenario, active use of ultrasonography, nonstress test and continuous fetal heart rate monitoring has led to increase in diagnosis of fetal distress.

In the current analysis the rate of caesarean section in primigravidae was observed as $29.1 \%$, which is almost double the accepted upper norm of WHO ie. $15 \%$. This study was conducted at a tertiary care hospital and medical college which is situated in the capital of the country. As such, vast majority of the cases attending the OPD and also those availing the emergency services are referred cases from the nearby hospitals thereby partly explaining the higher rate of caesarian deliveries. The incidence rates of caesarean section in primigravidae in tertiary hospital in the studies conducted by Das RK et al, Gupta M et al, Saxena N et al, Subhashini R et al, Naheed et al, Yadav RG et al, Singh G et al, Padmaleela K et al, J Honglei et al respectively are mentioned in Table $6 .^{6-14}$

Table 7: Indication of caesarean sections in primigravidae.

\begin{tabular}{|ll|lllllll|}
\hline Indication & $\begin{array}{l}\text { Sarma P } \\
\text { et al }\end{array}$ & $\begin{array}{l}\text { Jawa A } \\
\text { et al }^{18}\end{array}$ & $\begin{array}{l}\text { Chavda D } \\
\text { et al }\end{array}$ & $\begin{array}{l}\text { Bade P } \\
\text { et al }^{20}\end{array}$ & $\begin{array}{l}\text { Nikhil A } \\
\text { et al }\end{array}$ & $\begin{array}{l}\text { Balci O } \\
\text { et al }\end{array}$ & $\begin{array}{l}\text { Singh G } \\
\text { et al }\end{array}$ & $\begin{array}{l}\text { Present } \\
\text { study }\end{array}$ \\
\hline Arrest of labur & $2.02 \%$ & $5.93 \%$ & $4.80 \%$ & $17.60 \%$ & $6.32 \%$ & $9.88 \%$ & $5.10 \%$ & $17.87 \%$ \\
\hline CPD & $30.99 \%$ & $16.06 \%$ & $19.10 \%$ & $11.70 \%$ & $10.94 \%$ & $13.17 \%$ & $12.10 \%$ & $8.17 \%$ \\
\hline Fetal distress & $2.99 \%$ & $13.00 \%$ & $0.90 \%$ & $16.60 \%$ & $10.94 \%$ & - & $25.40 \%$ & $19.77 \%$ \\
\hline Breech/malpresentation & $3.03 \%$ & $9.37 \%$ & $18.60 \%$ & $6.80 \%$ & $8.26 \%$ & $5.48 \%$ & $11.30 \%$ & $8.93 \%$ \\
\hline Oligohydroamnios/IUGR & $5.00 \%$ & $5.93 \%$ & $2.00 \%$ & $4.00 \%$ & $3.80 \%$ & - & - & $10.26 \%$ \\
\hline Failed induction & $14.00 \%$ & - & $7.30 \%$ & $2.90 \%$ & - & $3.11 \%$ & - & $7.22 \%$ \\
\hline
\end{tabular}

Majority of the cases belonged to age group of 20-30 years $(79.34 \%)$. A significant proportion of women (18\%) belong to the age group 30 years and above and $2.5 \%$ of women among them were more than 35 years of age. This section of elderly primigravidae cannot be ignored as their population will rise in future due to increasing level of education, higher age of marriage and child bearing. Advanced maternal age can be associated with a number of maternal and neonatal complications and consequences including gestational diabetes, placenta previa, abruptio placenta, pre-eclampsia and cesarean section. In a study conducted in Ottawa Research Institute, Canada it was observed that the rate of caesarean section increased from $26.2 \%$ in maternal age group 20-34 years to $35.9 \%$ and $43.1 \%$ in age group 35 40 years and over 40 years respectively. ${ }^{15}$

Out of the total number of primigravidae caesarean deliveries, $67.2 \%$ were performed in emergency and $32.8 \%$ were performed electively. Our hospital being tertiary care center, also attends to the obstetric emergencies from periphery which adds to the emergency caesarean section census. Also, with intensive cardiotocographic monitoring of fetus, there has been a rise in the detection of fetal distress leading to caesarean section, which has been the most common indication of emergency caesarean section in present study.

Among the emergency caesarean sections performed, $56.3 \%$ of patients had induction of labor and $21.5 \%$ were in spontaneous labor. Around $16 \%$ of patients were operated before going into labor. It has been observed that medical disorders in pregnancy like diabetes and hypertensive disorders as well as fetal growth restriction have increased due to increased proportion of mothers with advanced gestational age, obesity, females undergoing assisted reproductive techniques. This has led to increasing trend towards induction of labor. Failed induction has thus become a significant contributor towards caesarean sections. Appropriate case selection for induction of labor taking into account the bishop score and urgency of the indication, will help in reducing unnecessary induction failures. In a study conducted in a tertiary hospital in Karnataka, India (2017) the induction of labor group was associated with increase in cesarean section rates of up to $31 \%$ when compared to that of spontaneous group which is $12 \%$. This is statistically significant with a $p$ value of $<0.001$. The rate of caesarean section in primigravidae induced women was $51 \%$ and $20 \%$ in spontaneous labor group. ${ }^{16}$

Most of the common indications of caesarean sections were due to non-recurrent causes such as fetal distress $(19.77 \%)$, arrest of labor $(17.87 \%)$, failed induction (7.22\%), multiple gestation $(5.7 \%)$. These patients can be good candidates for trial of normal labor in next pregnancy after taking into account other factors for vaginal delivery. It is this potential group of patients that should monitored carefully and all efforts should be made to avoid operative delivery. Senior and experienced obstetrician's opinion should be sorted before proceeding for operative intervention.

Various indications of caesarean section in primigravidae in tertiary hospital in percentages observed in studies conducted by Sarma et al, Jawa et al, Chavda et al, Bade et al, Nikhil A et al, and Balci $\mathrm{O}$ et al, respectively are depicted in Table $7 .{ }^{17-22}$ The most common indication of caesarean section in primigravidae in present study was fetal distress (19.77\%), followed by arrest of labor 
(17.87\%). This is comparable to the study conducted by Jawa et al, and Nikhil A et al. ${ }^{18,21}$ Intensive intrapartum fetal monitoring by cardiotocography and real time ultrasound has led to increase in diagnosis of fetal distress. The present study was conducted in a tertiary hospital where round the clock facilities of surveillance intensive feto-maternal, ultrasound imaging for biophysical profile, color Doppler and cardiotocography are available, leading to prompt diagnosis of fetal distress.

Arrest of labor is a very common indication for caesarean section. Evidence based labor management is a concept to be adapted for curbing the caesarean rate. The Consortium on Safe Labor data (ACOG 2016) do not directly address an optimal duration for the diagnosis of active phase protraction or labor arrest, but do suggest that neither should be diagnosed before $6 \mathrm{~cm}$ of dilation with membrane rupture and 4 hours or more of adequate contractions or 6 hours or more of inadequate contractions and no cervical change. Before diagnosing arrest of labor in the second stage and if the maternal and fetal conditions permit, at least 2 hours of pushing in multiparous women and at least 3 hours of pushing in nulliparous women should be allowed. ${ }^{23}$

Another frequently encountered indication is malpresentations. Though external cephalic version for fetal malpresentation if successful will likely lead to vaginal delivery, the skill is likely underutilized. Obstetricians should offer and perform external cephalic version whenever possible.

Variations in the management of labor induction likely affect rates of cesarean delivery, particularly the use of cervical ripening agents for the unfavorable cervix and the lack of a standard definition of what constitutes prolonged duration of the latent phase. Studies have found that the use of cervical ripening methods such as misoprostol, dinoprostone, prostaglandin E2 gel, Foleys bulb lead to lower rates of cesarean delivery. Cesarean deliveries for failed induction of labor in the latent phase can be avoided by allowing longer durations of the latent phase (up to 24 hours or longer) and requiring that oxytocin be administered for at least 12-18 hours after membrane rupture before deeming the induction a failure. $^{23}$

The rate of cesarean deliveries among women with twin gestations increased in past decade. Perinatal outcomes for twin gestations in which the first twin is cephalic are not improved by cesarean delivery. Hence women with twin pregnancy with first cephalic presentation should be counseled to attempt vaginal delivery. ${ }^{23,24}$

A phenomenal rise in the Assisted Reproductive Techniques due to rising rate of infertility and advanced maternal age has also led to increase in caesarean sections. Most of the higher order gestations are a result of ART and becomes very precious for the patient and the treating doctor. Studies to date have shown that following the policy of single embryo transfer reduces the multiple pregnancy rate to virtually zero while having pregnancy rate comparable to double embryo transfer. Preterm delivery is also common in such pregnancies. Use of tocolytic agents, steroid and the desire for safe outcome also causes increased operative delivery. Selective fetal reduction is also a good technique and should be incorporated where ever needed to decrease the incidence of multiple pregnancies. ${ }^{25}$

There should also be effective counselling of the couple for proper birth spacing options. Short-inter-conception period also becomes an indication for elective repeat caesarean section in future pregnancy.

The morbidity rate in caesarean section in our study was $25.4 \%$ with wound infection being most common (9\%), spinal headache second most common $(8.8 \%)$ and postpartum hemorrhage being the next $(5.2 \%)$. Blood transfusion was required in $2.5 \%$ of the patients. PPH is one of the deadliest complication for an obstetrician and patient. They are exposed to the risks associated with massive blood transfusion, prolonged surgical time, infections and caesarean hysterectomy. The incidence of PPH has risen even in western countries. It is still a very important cause of maternal mortality. The incidence of fever and UTI was $2 \%$ and $2.5 \%$ respectively. In a study by Osman Balci et al, morbidity rate was found as $14 \%$. Febrile morbidity was detected as the most common with $11 \% .^{22}$ There was one mortality on the first postoperative day due to thromboembolism. Postoperative endometritis, urinary tract infection and wound infection rates were detected $1.28 \%, 1.09 \%$ and $0.73 \%$ respectively. In a study by Santhanalakshmi C et al, the commonest complication was wound infection, $38 \%$ being the morbidity rate. ${ }^{26}$

\section{CONCLUSION}

The alarmingly high rate of caesarean section needs immediate attention. In this study group of primigravidae women undergoing caesarean delivery, examination of the indications revealed potential targets to reduce primary caesarean section rate. It is important to realize that reducing the primary caesarean rate not only decreases total caesarean rate but also many long-term complications associated with previous caesarean sections. Patients being operated for non-recurrent indications should be reassessed and guidance from senior obstetrician should be sorted. The implementation of evidence based clinical practice guidelines, proper patient selection for labor induction, judicious use of cardiotocography and ultrasound to prevent overdiagnosis of various indications, regular caesarean delivery audit and timely feedback to health professionals is strongly recommended. Along with these education and awareness of antenatal women is equally important in effectively lowering the rate of caesarean section. 
Funding: No funding sources

Conflict of interest: None declared

Ethical approval: Not required

\section{REFERENCES}

1. Caesarean section on the rise. The Lancet. 2000;356:1697.

2. Belizán JM, Cafferata ML, Althabe F, Buekens P. Risk of patient choice caesarean. Birth. 2006;33:1679.

3. Caughey AB, Cahill AG. Safe prevention of the primary cesarean delivery. Obstetric Care Consensus. 2014;1:2-19.

4. Hannah ME. Planned elective cesarean section: a reasonable choice for some women? CMAJ. 2004;170:813-4.

5. Minkoff H, Chevenak FA. Elective primary caesarean delivery. N Engl J Med. 2003;348:946-50.

6. Das RK. Changing Trends in Caesarean Section; Rate and Indications. Int $\mathrm{J}$ Contemp Pediatr. 2018;5(5):1733-9.

7. Gupta M, Garg V. The rate and indications of caesarean section at a tertiary care centre in Jaipur, India. Int J Reprod Contracept Obstet Gynecol. 2017;6(5):1786-92.

8. Saxena N, Sharma B, Gupta V, Negi KS. A six year appraisal of caesarean delivery at a teaching hospital In Uttarakhand. Int $\mathrm{J}$ Reprod Contracept Obstet Gynecol. 2016;5:4369-72.

9. Subhashini R, Uma N. Changing trends in caesarean delivery. IAIM. 2015;2(3):96-102.

10. Naheed I, Malik S, Akhtar M, Khatri N. An audit of increasing caesarean section rate in primigravidae. $\mathrm{P}$ J M H S. 2014;8(4):1012.

11. Yadav RG, Maitra N. Examining cesarean delivery rates using the Robson's ten group classification. J Obstet Gynecol India. 2016;66(Suppl 1):1.

12. Singh G, Gupta ED. Rising incidence of caesarean section in rural area in haryana, india: a retrospective analysis. Internet J Gynecol Obstet. 2013;17(2):1-5.

13. Padmaleela K, Thomas V, Prasad KV. An analysis of the institutional deliveries and their outcomes in government teaching hospitals of Andhra Pradesh, India. IJHSR. 2013;3(5):76-81.

14. Ji H, Jiang H, Yang L. Factors contributing to the rapid rise of caesarean section: a prospective study of primiparous Chinese women in Shanghai. BMJ Open. 2015;5:e008994.

15. Janoudi G, Kelly S, Yasseen A, Hamam H, Walker M. Factors associated with increased rates of caesarean section in women with advanced maternal age. J Obstet Gynaecol Can. 2015;37(6):517-26.
16. Babu S, Manjeera ML. Elective induction versus spontaneous labor at term: prospective study of outcome and complications. Int J Reprod Contracept Obstet Gynecol. 2017;6(11):4899-907.

17. Sarma P, Boro RC, Acharjee PS. An analysis of indications of caesarean sections at tezpur medical college and hospital, Tezpur (A Government Hospital). Int J Reprod Contracept Obstet Gynecol. 2016;5:1364-7.

18. Jawa A, Garg S, Tater A, Sharma U. Indications and rates of lower segment caesarean section at tertiary care hospital-an analytical study. Int $\mathrm{J}$ Reprod Contracept Obstet Gynecol. 2016;5:3466-9.

19. Chavda D, Goswam K, Dudhrejiva K. A cross sectional study of 1000 lower segment cesarean section in obstetrics and gynecology department of P. D. U medical college, Rajkot, Gujarat, India. Int J Reprod Contracept Obstet Gynecol. 2017;6(4):118691.

20. Bade P, Kendre V, Jadhav Y, Wadagale A. An analysis of indications for caesarean section at government medical college, Latur. Intern J Recent Trends Sci Technol. 2014;11(1):6-8.

21. Nikhil A, Desai A, Vijay K, Bhumika K, Riddhi P. Analysis of trends in LSCS rate and indications of LSCS: a study in a medical college hospital GMERS, Sola, Ahmedabad. Int J Pharm Bio-Sci. 2015;2(1):15.

22. Balci O, Gezginc K, Acar A. The outcome analysis of cesarean section cases in one-year period. Gynecol Obstet Reprod Med. 2007;13:6-28.

23. Safe prevention of the primary cesarean delivery. obstetric care consensus no. 1. American College of Obstetricians and Gynecologists. ObstetGynecol. 2014;123:693-711.

24. Chaillet N, Dumont A. Evidence-based strategies for reducing cesarean section rates: a meta-analysis. Birth. 2007;34:53-64.

25. Kosmas I, Van der Elst J, Devroey P, Tournaye H. Elective single embryo transfer. The Obstetrician Gynaecol. 2008;10:163-70.

26. Santhanalakshmi C, Gnanasekaran V, Chakravarthy AR. A retrospective analysis of cesarean section in a tertiary care hospital. Int J Reprod Contracept Obstet Gynecol. 2015;4:2097-9.

Cite this article as: Datta K, Singh P, Chopra N. Retrospective analysis of indications of primary caesarean sections done at a tertiary care hospital. Int J Reprod Contracept Obstet Gynecol 2019;8:3161-7. 